\title{
Deformidad vertebral en el Síndrome de Noonan: revisión de la literatura. A propósito de dos casos
}

Leonor Gijón Moreno, Cristina Varela Lage, Elena Villalobos Baeza, Estrella García Sánchez, Carolina de Miguel Benadiba

\author{
Servicio de Medicina Física y \\ Rehabilitación \\ Hospital Universitario Ramón y Cajal. \\ Madrid - España
}

\section{Correspondencia:}

\section{Leonor Gijón Moreno}

”l leox_11@hotmail.com

Keywords: Sindrome Noonan, Escoliosis, Alteraciones esqueléticas, Rehabilitación.

\section{INTRODUCCIÓN}

El síndrome de Noonan es un trastorno autosómico dominante, de expresividad muy variable caracterizado por talla baja, cardiopatía congénita (la alteración congénita más frecuente), dimorfismo facial y alteraciones esqueléticas [1,2]. Además puede presentar: retraso psicomotor, diátesis hemorrágica, linfedema crónico, alteraciones auditivas, criptorquidia y alteraciones morfológicas renales [1-3]. Entre las anomalías vertebrales descritas en la literatura la escoliosis es la más frecuentemente descrita con prevalencias que oscilan entre el 10 y $15 \%$ de los casos [4-8]. La incidencia de esta enfermedad se estima en 1 de cada 2500 recién nacidos vivos [7]. Los genes relacionados (PTPN1, RAF1, SOS1 y KRAS) están implicados en la vía de señalización intracelular RAS-MAPK, vía compartida con otros síndromes raros con los que se debe hacer el diagnóstico diferencial (síndrome de Turner, síndrome cardiofaciocutaneo, Costello, Leopard y la Neurofibromatosis tipo 1) $[4,6]$. El diagnóstico es clínico, aunque a nivel mo- 
lecular el diagnóstico podría confirmar las sospechas en pacientes pediátricos con rasgos de sospecha y contribuir a definir el riesgo de comorbilidades[1,7]. Actualmente no tiene tratamiento específico, aunque aquellos de baja talla puede considerarse el uso de hormona de crecimiento $(\mathrm{GH})$ [6], considerando que si son tratados con esta hormona y asocian deformidad vertebral, ésta debe ser revisada de forma estrecha, para que no aumente su valor angular.

\section{CASOS CLÍNICOS}

Presentamos dos casos de escoliosis asociadas al síndrome de Noonan atendidos en nuestro servicio.

\section{Caso 1}

Paciente de 42 años producto de un parto prematuro y peso al nacer 2.090 kg, desarrollo psicomotor con deambulación a los 2 años y retraso escolar de un año. Antecedentes familiares sin interés. Antecedentes personales: Comunicación inter auricular (CIA) tipo ostium secundum, estenosis válvula pulmonar y miocardiopatía hipertrófica. Presentaba dismorfia facial, hipocrecimiento, criptorquidia bilateral (orquidopexia izquierda, orquidectomia derecha con prótesis testicular), deformidad vertebral, linfoangiomas y angioqueratoma en escroto y región inguinal así como hiperplasia gingival y faringitis hipertrófica.

Presentaba un cariotipo masculino normal $46 \mathrm{XY}$. Fue valorado por un servicio de rehabilitación a los 12 años iniciandose tratamiento con cinesiterapia, sin manejo ortopédico asociado. Dada la evolución de la deformidad, deciden remitirlo a nuestro Servicio a la edad de 20 años, edad a la que presentaba los siguientes hallazgos:

Facies con pabellones auriculares de implantación baja, pegados; macroglosia; cuello ancho con ligero pterigium; torax en quilla; amiotrofia de las 4 extremidades; anteversión de tronco; ausencia de vello en axilas y extremidades, escaso pubiano. Talla 1,50 cm. Columna: escápula derecha $30 \mathrm{~mm}$ más alta que la izquierda, giba torácica derecha $55 \mathrm{~mm}$, eje occipito-sacro (EOS) desviado $20 \mathrm{~mm}$ hacia la derecha, distancia dedo-suelo (DDS) $25 \mathrm{~mm}$, flechas cervical $80 \mathrm{~mm}$ y lumbar $90 \mathrm{~mm}$. (Fig. 1)

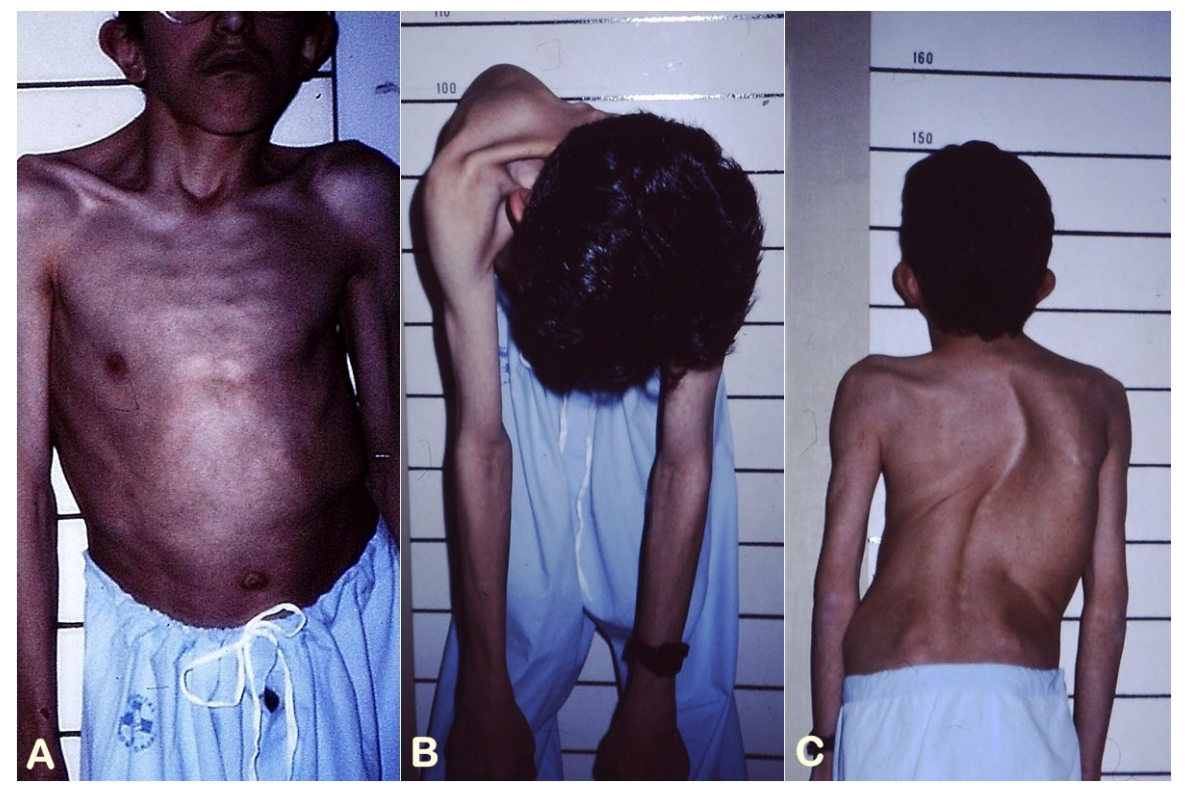

Figura 1. (A) Aspecto anterior del tórax. (B) Test de Adams mostrando giba torácica derecha. (C) Desviación del eje occipucio-sacro a la derecha. 
En la teleradiografía anteroposterior de columna se observó escoliosis torácica derecha con valor angular $110^{\circ}$ (vértebras límites T1-L2, vértice T7), Test de Risser 5. (Fig 2)

En la prueba de función respiratoria se observó una restricción ventilatoria grado III motivo por el que se desestimó el manejo quirúrgico.

Ha estado en seguimiento durante 22 años con disminución de la estatura respecto a la inicial, aumento de $20 \mathrm{~mm}$ de la gibosidad, sin variabilidad con respecto al valor angular de la curva, las flechas, el EOS y las pruebas de función respiratorias.

\section{Caso 2}

Paciente de 26 años con embarazo y parto normales, desarrollo psicomotor normal y antecedentes familiares sin interés. En sus antecedentes personales destacaban: Tetralogía de Fallot y fístula arteriovenosa intervenidas con cierre de la comunicación interventricular, desinserción de la fístula, ampliación transanular de tronco supraventricular derechos y ampliación de la arteria pulmonar derecha. El paciente presentaba dismorfia facial, hipocrecimiento, deformidad vertebral. Presentaba un cariotipo masculino normal $46 \mathrm{XY}$.

Fue remitido al servicio de Rehabilitación con 14 años para valorar su deformidad vertebral.

En la exploración física presentaba: facies triangular, implantación baja del cabello, microstomía, paladar ojival estrecho, Pterigium colli, tórax triangular, pectus excavatum, miembros más desarrollados que el tronco. Exploración de Columna: Talla $1.32 \mathrm{~cm}$, giba torácica izquierda de $25 \mathrm{~mm}$, EOS centrado, distancia dedos-suelo $32 \mathrm{~mm}$, flechas cervical y lumbar $70 \mathrm{~mm}$.

En la teleradiografía anteroposterior y lateral se apreciaba hipercifosis con valor angular $65^{\circ}$ (vértebras límites T1-T12, vértice T6) y escoliosis torácica derecha de $15^{\circ}$ con test de Risser 0. (Fig 3)

Se le colocó un yeso corrector en suspensión, con retirada a los dos meses y posterior uso de un corsé de Swain que debía llevar 23 h al día.

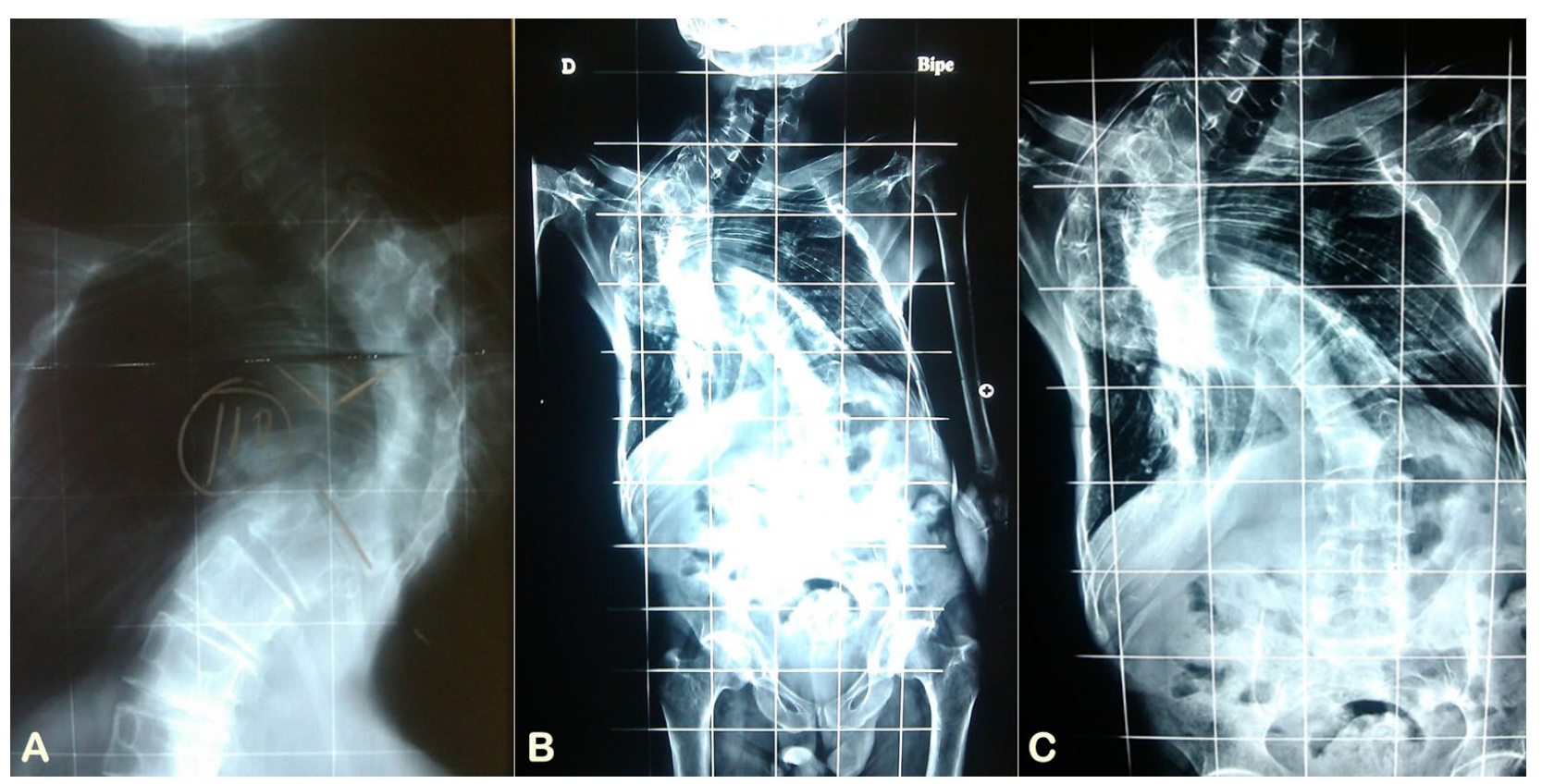

Figura 2. (A) Teleradiografía anteroposterior mostrando escoliosis de $110^{\circ}$ desde una proyección invertida. (B) y (C) Teleradiografía anteroposterior convencional y detalle torácico. 
En su evolución, con seguimiento hasta los 20 años de edad, el paciente no cumplía con el tratamiento. La talla aumentó $15 \mathrm{~cm}$, la flecha dorsal no se modificó y la lumbar aumentó 30 mm, y el valor angular de las curvas permaneció estable con $70^{\circ}$ de cifosis y $15^{\circ}$ de escoliosis torácica derecha.

\section{DISCUSIÓN}

El síndrome de Noonan debe sospecharse en pacientes con hipocrecimiento, dismorfia facial, cardiopatía congénita y deformidad esquelética. La deformidad vertebral asociada a este síndrome está poco descrita en la literatura. El diagnóstico diferencial se debe hacer con otros síndromes en base a la historia clínica, las pruebas de imagen y estudio genético. No existe tratamiento específico, sólo de las complicaciones. Se desarrolla a edades tempranas y es relativamente severa, razón por la cual es esencial hacer un diagnóstico precoz e iniciar el tratamiento de forma temprana para evitar futuras complicaciones.

\section{CONCLUSIÓN}

El síndrome de Noonan debe sospecharse en pacientes con hipocrecimiento, dismorfia facial, cardiopatía congénita y deformidad esquelética. La deformidad vertebral asociada a este síndrome está poco descrita en la literatura. El diagnóstico diferencial se debe hacer con otros síndromes en base a la historia clínica, las pruebas de imagen y estudio genético.

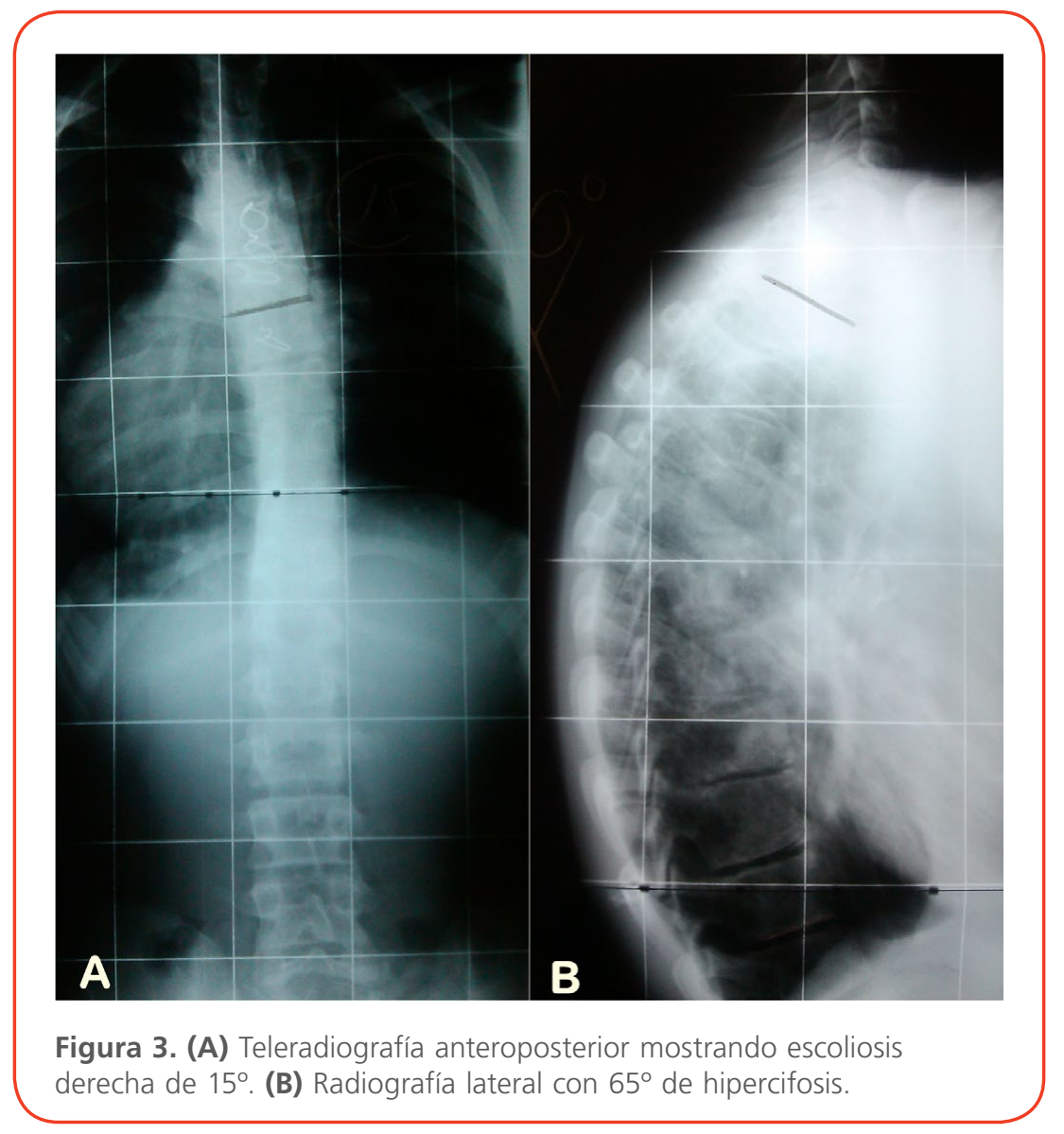




\section{BIBLIOGRAFÍA}

1. Robert AE, Allanson JE, Tartaglia M, Gelb BD. Noonan syndrome. Lancet. 2013. Jan 26;381 (9863): 333-42.

2. Cammarata-Scalisi $F$, et al. Clinical and molecular study of the Noonan syndrome. Invest Clin. 2012 Dec;53(4):395-401.

3. Noonan JA. Noonan syndrome and related disorders: alterations in growth and puberty. Rev Endocr. Metab. Disord. 2006 Dec; 7(4):251-5.

4. Jorge AA, Malaquias AC, Arnhold IJ, Mendonca BB. Noonan syndrome and related disorders: a review of clinical features and mutations in genes of the RAS/MAPK pathway. Horm Res. 2009;71(4):185-93.

5. Romano AA, Allanson JE, Dahlgren J, Gelb BD, Hall B, Pierpont ME, Roberts $A E$, Robinson W, Takemoto CM, Noonan JA. Noonan syndrome: clinical features, diagnosis, and management guidelines. Pediatrics. 2010 Oct;126(4):746-59.

6. Tartaglia M, Gelb BD, Zenker M. Noonan syndrome and clinically related disorders. Best Pract Res Clin Endocrinol Metab. 2011 Feb; 25(1): 161-179.

7. Van der Burgt I. Noonan syndrome. Orphanet J Rare Dis. 2007 Jan; 2: 4.

8. Lee CK, Chang BS, Hong YM, Yang SW, Lee CS, Seo JB. Spinal deformities in Noonan syndrome: a clinical review of sixty cases. J.Bone Joint Surg Am. 2001 Oct;83-A(10):1495-502.

9. Smpokou P, Tworog-Dube E, Kucherlapati RS, Roberts $A E$. Medical complications, clinical findings, and educational outcomes in adults with Noonan syndrome. AM J Med Genet A. 2012 Dec;158A(12):3106-11.
Opina sobre este artículo:
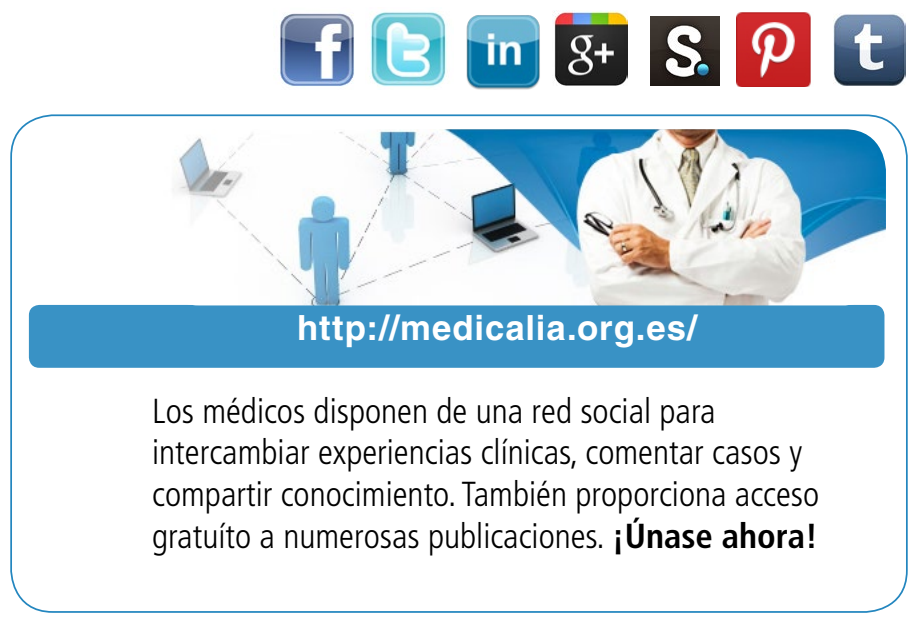

\section{Publish with iMedPub}

http://www.imed.pub

Acta Reumatológica es una revista que tiene por fin la difusión de estudios clínicos relacionados con aspectos prácticos del diagnóstico, tratamiento y seguimiento de pacientes con patología reumatológica, de estudios epidemiológicos relacionados con patología inflamatoria y musculoesquelética de presentación común o infrecuente en la práctica clínica tanto en población adulta como pediátrica, de casos clínicos de patología poco habitual o de presentaciones inhabituales de patología frecuente, de imágenes didácticas e ilustrativas en reumatología y del estado actual e innovación en la formación especializada en reumatología. 